\title{
中層トロールシステムの静的特性の解析法*1
}

\author{
胡夫祥, 松田㛺
}

(1991 年 1 月 7 日受付)

\section{An Analytical Method of Static Characteristics of Midwater Trawl System}

\author{
Hu Fuxiang*2 and Ko Matuda*2
}

Equilibrium differential equations of motion for a three dimensional midwater trawl system, which consists of warp, otter board and trawl net were introduced. A new analytical method that was solved from the side of net as initial conditions was developed. A computer simulation was made and the results were compared with those of the field experiments on the midwater trawl system of FRV "Shinyo-maru" belonging to the Tokyo University of Fisheries. There was good agreement between simulation and experiment on the working depth of the otter board and the net. However, in regard to the spread of wingend, it was observed that the difference between both increased with the warp length. This is supposed that the attack angle of otter board was not always settled in perfect condition.

トロールシステムを構成するワープの形状和よび張力 分布などの解析法については, 寸でに宮崎, ${ }^{1-4)}$ 佐藤·宮 菏, ${ }^{5)}$ Nakasai and Kawakami ${ }^{8)}$ 特よび She et al. ${ }^{7)}$ 上る近似計算法が報告されている。しかし，それらはい ナ゙れもいわゆるケーブルの問題に限られ、ワーブ、オッ ターボードおよび絧とを組合わせた三次元の中層トロ一 ル網のシステムとしての解析はまた充分に解明されてい るとは言えない。さらに, 漁船の史絧条件と漁場環境な どを考慮して漁具を設計するためには，網の規模やシス テムの運動状態を定量的に把握しておく必要がある。

本論文では，定常運動状態に和ける中圈トロールシス テムを構成するワープ、ブライドルなどローブ類の釣合

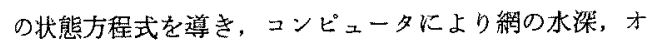
ッターの水深および袖絧問隔などの数值解を求めた。理 論から得られた計算值と海上実験による实測值とを比較 した。さらに，この解析法を用いて，中層トロールシス テムのワープ長および曳網速度などの主要ハララータが 網の水深, 袖網間隔などK及ぼす影響をシミュレーショ ンにより検討した。

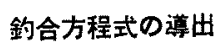

水中に括いて任意の運動をしている伸びない均質で, 柔軟なロープの一定点から $\mathrm{P}$ 点までの長さを $s$ とし, $s と s+d s$ との間の徽小長さ $d s$ に作用する外力の合力 ベタトルを $\boldsymbol{R} d s$, ロープの各点に働くsの增加する向き の張力ベタトルを $T(s, t)$, ロープの単位長さの質量を $m$
とすると、このッープの一般運動方程式は

$$
m \frac{\partial^{2} \boldsymbol{r}}{\partial \boldsymbol{t}^{2}}=\boldsymbol{R}+\frac{\partial \boldsymbol{T}}{\partial s}
$$

と表される。ここで, $r(s, t)$ は $P$ 点の位置ベクトルです 当。

このローブが定常運動を保っているときには，(1) 式

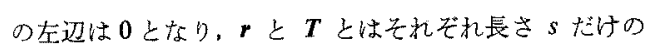
関数になるから，Fig. 1 に示すような史網方向を $x$ 朝，

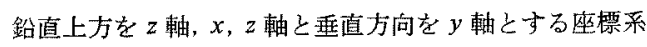
において，ロープの単位長さ $d s$ に作用する流体力の $x$, $y ， z$ 軸成分を艺れぞれ $R_{x} ， R_{y} ， R_{z}$ とすると，この座磦 系に関する定常運動に括ける一般の釣合方程式として (1) 式よb

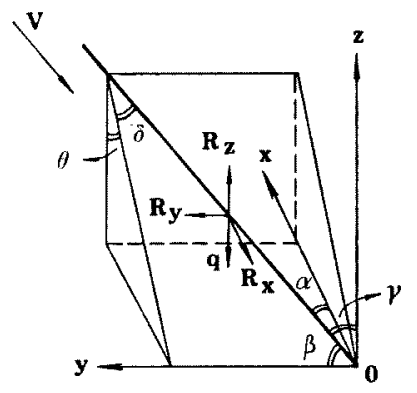

Fig. 1. Diagram of coodinate axis.

*1 本論文の大要は平成元年度日本水産学会年会（東京）において埌告した。

*2 東京水座大学 (Tokyo University of Fisheries, Konan, Minato, Tokyo 108, Japan). 


$$
\left.\begin{array}{l}
\frac{d}{d s}(T \cos \alpha)-R_{x}=0 \\
\frac{d}{d s}(T \cos \beta) \pm R_{y}=0 \\
\frac{d}{d s}(T \cos \gamma)+R_{z}=0
\end{array}\right\}
$$

が遖かれる。この（2）式を中層トロールシステムを構成 するワープなどローブ類の定常運動における張力乱よび 形状の暲算に用いる。この量合， $\alpha, \beta, \gamma$ はそれでれワ一 ブまたはブライドルなどの任意の位直に和ける張力Tの $x, y, z$ 朝との成方角度である。(2) の第二式の第一項に

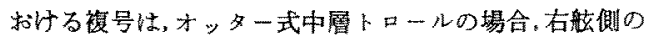
ワープ怙よび左舷側のブライドルを対象上する時は正。

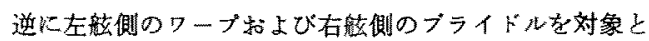
する時は負をとる。しかし，中㬝トロールは左右対称で あると見なせるので、以下名舷側のワープの双を取报う。

传落ら゙によれば, ワイヤ 流体力保数はそれでれ

$$
\begin{aligned}
& C_{x}=C_{D 0}\left(1-\sin ^{2} \theta \cos ^{2} \delta\right) \\
& C_{y}=C_{D 0} \sin \theta \cos \delta \frac{\sin ^{2} \delta}{\sqrt{1-\cos ^{2} \theta \cos ^{2} \delta}} \\
& C_{z}=C_{D 0} \sin \theta \cos ^{2} \theta \cos ^{2} \delta
\end{aligned}
$$

と表される。たたし，CD惊，ワイヤロープが流れに值 角に置かれたときの抗力係数で，次式で表される。

$C_{D 0}=2.086\left(R_{e}\right)^{-0.08}\left(3 \times 10^{3}<R_{e}<1 \times 10^{4}\right)$

$こ こ K, R_{e}=V d / \nu(V:$ 安絧速度， $d: \nabla イ ヤ ロ-700$

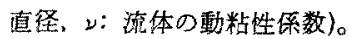

Fig. 1 亿示可幾何学的関係より，(3) 式に拈方角度

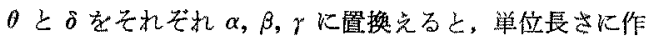
用する流体力口 $x, y, z$ 軸の成分性，在れでれ次式で表 される。

$$
\left.\begin{array}{l}
R_{x}=k V^{2}\left(1-\cos ^{2} \alpha\right) \\
R_{y}=k V^{2} \frac{\cos \alpha \cos ^{2} \beta}{\sqrt{1-\cos ^{2} \gamma}} \\
R_{z}=k V^{2} \sqrt{\sqrt{1-\cos ^{2} \beta}}
\end{array}\right\}
$$

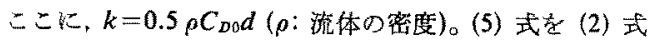
に代入し，次の上ちな变数变換を行ら

$$
\begin{aligned}
& \tau=T / W_{B} \quad \sigma=s / l_{n}, \quad \xi=x / h_{n} \\
& \eta=y / l_{n}, \quad \zeta=z / l_{n}, \quad \kappa=k l_{n} V^{2} / W_{B} \\
& \phi=I_{n} q / W_{B}
\end{aligned}
$$

(6) 式で定義された各変数はすべて無次元量で，qは口 一プの単位長さの水中重琵, $l_{n}$ は網の全舆， $W_{B}$ はオッ ター粉ートの水中重量でする。このよらにして得ら就た

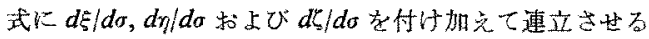

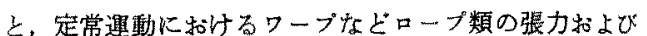
形状を求める無次元の釣合方程式

$$
\begin{array}{r}
\frac{d \tau}{d \sigma}=\kappa \sqrt{1-\cos ^{2} \beta-\cos ^{2} \gamma}\left(\cos ^{2} \beta+\cos ^{2} \gamma\right. \\
\left.-\frac{\cos ^{3} \beta}{\sin \gamma}-\frac{\cos ^{8} \gamma}{\sin \beta}\right)+\phi \cos \gamma
\end{array}
$$

$\frac{d \beta}{d \sigma}=\frac{\kappa}{\tau} \cot \beta \sqrt{1-\cos ^{2} \beta-\cos ^{2} \gamma}\left(\cos ^{2} \beta+\cos ^{2} \gamma\right.$ $\left.-\frac{\cos \beta \sin ^{2} \beta}{\sin \gamma}-\frac{\cos ^{3} \gamma}{\sin \beta}\right)+\frac{\phi}{\tau} \cot \beta \cos \gamma$

$\frac{d \gamma}{d \sigma}=\frac{k}{\tau} \cot \gamma \sqrt{1-\cos ^{2} \beta-\cos ^{2} \gamma}\left(\cos ^{2} \beta+\cos ^{2} \gamma\right)(\gamma$

$$
\left.-\frac{\cos \gamma \sin ^{2} \gamma}{\sin \beta}-\frac{\cos ^{8} \beta}{\sin \gamma}\right)-\frac{\phi}{\tau} \sin \gamma
$$

$\frac{d \xi}{d \sigma}=\sqrt{1-\cos ^{2} \beta-\cos ^{2} \gamma}$

$\frac{d \eta}{d \sigma}=\cos \beta$

$\frac{d \zeta}{d \sigma}=\cos \gamma$

が得られる。

（7）式は網の袖先を匴算の始点とするワーブなどロー ブ類の誩力机よび形状を求める鈞合方程式であるから， 袖先に括汸初期条件を得るために，ここでは，定常運

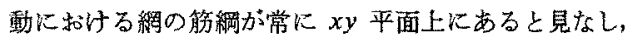
また網の浮力 $F$, 沈降力（フッントウェイトを合む） $W_{n}$ 拉よび絧の抵抗 $R$ は，すべて袖先の $O$ 点に集約すると 近似する。ただし，中罢トロ一ル網の抵抗 $R$ について は、次の推定式*用いる。

$$
R=\frac{1}{2} \rho V^{2} C_{D N} S_{T}
$$

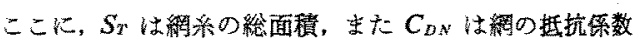
で，網の全長 $\left(l_{n}\right)$ を代表長さとするレイノルズ数 $\left(R_{e}\right)$ の閶数として表される $\left(C_{D N}=3.02 R_{e}^{-0.13 n}\right)$ 。

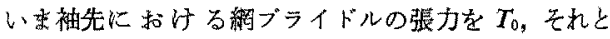
$x, y, z$ 軸とのなす角度をとれぞれ $\alpha_{0}, \beta_{0}, \gamma_{0}$ とすると， 力口釣合加方袖先飞和汀方無次元化した初期条件は次式 はなる。

$$
\begin{gathered}
\tau_{0}=\frac{1}{2} \sqrt{\left(1+\lambda^{2}\right) \phi^{2}+(\omega-v)^{2}} \\
\hat{\beta}_{0}=\cos ^{-1}\left(\frac{\lambda \varphi}{2 \tau_{0}}\right) \\
\lambda_{0}=\cos ^{-1}\left(\frac{\omega-v}{2 \tau_{0}}\right) \\
\sigma_{0}=\xi_{0}=\zeta_{0}=0, \quad \eta_{0}=\frac{y_{0}}{l_{n}} \\
こ こ に, \lambda=\frac{y_{n}}{2 \sqrt{l_{n}^{2}-\left(\frac{3}{2} y_{n}\right)^{2}}}\left(y_{n}:\right. \text { 袖先間隔), }
\end{gathered}
$$

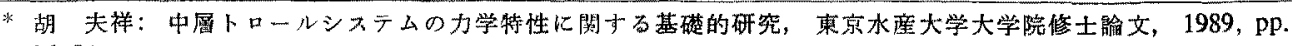
36-54.
} 


$$
\phi=\frac{R}{W_{B}}, \quad \omega=\frac{W_{n}}{W_{B}}, \quad \nu=\frac{F}{W_{B}} .
$$

次に，オッターボードに作用する力は，オッターボー トの揚力 $L$, 抗力 $D$ 扣よび本中重量 $W_{B}$, ハンドローブ の張力 $T_{H}\left(T_{H}\right.$ と $x, y, z$ 軸とのなす角度を $\alpha_{H}, \beta_{H}, \gamma_{H}$ と寸る。下付きの 数意昧する。以下略), ワープの張力 $T_{w}\left(T_{w}\llcorner x, y, z\right.$ 朝とのなす角度を $\alpha_{w}, \beta_{w}, \gamma$ とする。下付きの $w$ 性口 ープの計算における変数を意味する。以下略)である。 これらのカをすべてオッターボードの压力中心に集約す ると仮定すると、オッターボードに作用する力の釣合は

$$
\begin{aligned}
& T_{w} \cos \alpha_{w}=D+T_{H} \cos \alpha_{H} \\
& T_{w} \cos \beta_{w}=L-T_{H} \cos \beta_{H} \\
& T_{w} \cos \gamma_{w}=W_{B}+T_{H} \cos \gamma_{H}
\end{aligned}
$$

となる。ここで, (6) 式にならって，無次元量 $\mu_{B}=L / W_{B}$ 括よび $\phi_{B}=D / W_{B}$ を導入すると, (10) 式执よび $\cos ^{2} \alpha_{w}$ $+\cos ^{2} \beta_{w}+\cos ^{2} \gamma_{w}=1$ の関係から

$$
\begin{aligned}
& \tau_{w}=\sqrt{\left(\phi_{B}+\tau_{H} \cos \alpha_{H}\right)^{2}+\left(\mu_{B}-\tau_{H} \cos \beta_{H}\right)^{2}} \\
& +\left(1+\tau_{H} \cos \gamma_{H}\right)^{2}
\end{aligned}
$$

が得られる。

\section{解 析方 法}

前述のようK，曳絧中の中層トロールシステムの糊我 㳭，袖網間隔などを予測することは操業上極めて重要で ある。それらの計算について，仮に，曳航点（船尾）に 甜けるワープの張力および傾角が得られれば，电航点を 始点として計算するのが便利である。しかし，寒祭にお いて、ワープの傾角の正確な計測值を得ることは極めて 困難であり，仮にワープの傾角を初期値として計算した あのは，その計算方法が正確であっても，精度的には問 題があると思われる。このような理由から，本諭文では， 被电航点（袖先）を計算の始点に選んだ。

袖先から、網ブライドル，ハンドロープ脑よびワーダ の計算について，(7) 式で与克られた非線形常微分方程 式を四次のルンゲ・クッタ法を用いて数値計算すること にする。ただ，以下の解析例にあげた中層トロールで は,ブライドルが三本から棈成されているが，計算では 簡単のため，三本のブライドルをまとめて一本として取 报った。ここに,ブライトルの計算では， $\sigma_{0}=0$ におけ る初期条件として (9) 式を用いる。またワープの計算で は， $\sigma_{w}=0$ に和ける初期条件 (11)式と

$$
\xi_{w}=\xi_{H}, \quad \zeta_{w}=\zeta_{H}, \quad \eta_{w}=-\eta_{H}
$$

を用いるほか，电航点においては，船のトップローラの
間隔 $E$ の制約を受けるので，末端条件

$$
\eta_{e}=\frac{E}{2 l_{n}}
$$

を必要とする。計算では，袖網間隔などのパラィータ值 を変觅ることによって，末端条件汉収束するまで繰り返 于。

ここで, 前報の”の奏験に用いた神萑丸に装備した網を 例に計算を試みる。㬰測值上比較するため，オッターボ ード，ロープ類などシステム全体に関して，海上实験と 同一の值を用いだ。ただし，オッターボードの性能につ いては，海上実験に执いて必ずしも最大掦力の得られる 迎角で使用されているかどらか，断定できないので，計 算では。とれが常に最大揚力の得られる状態で使用され ていると仅定した。

な゙この諳算は収策するまでに相当の計算時間を要 し、特に計算ステップ SPによって左右されると考充ら れる。そこで、ルンゲ・クッタ法によるロープ類（ワー プ，ハンドロープおよびブライドルを含も）の計算ステ ップ SP とそれによる網水滐（または袖網間隔）の相対 誤差 $\varepsilon_{z}$ (杰たは $\varepsilon_{y n}$ ) との関保をワープ長 $400 \mathrm{~m}$, 曳網速 度 3ノットの場合について，Fig. 2 にプロットしてみ た。 $\varepsilon$ は次式に示寸占うに， $S P=1 \mathrm{~m}$ のときの網水滐 $z_{(1)}$ (または袖網間隔 $\left.y_{n(1)}\right)$ をもとに計算した。

$$
\varepsilon_{z}=\frac{\left|z_{(1)}-z_{(S P)}\right|}{z_{(1)}}
$$

Fig. 2 から，例党ば $S P=5 \mathrm{~m}$ とした時， $S P=1 \mathrm{~m}$ と した時の計算結果に対して $\varepsilon_{z}$ は $0.6 \%$ 以下， $\varepsilon_{y n}$ も $2 \%$ 以下となることが分かる。したがって，以降の計算はす

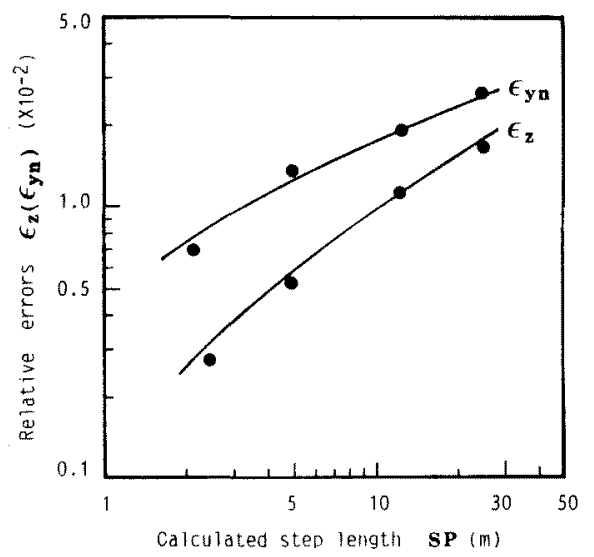

Fig. 2. Relationship between the relative errors of working depth of net and spread of wingend to the calculated step length (warp length $=400 \mathrm{~m}$, towing speed $=3 \mathrm{kt}$ ). $\varepsilon_{2}:$ relative error of working depth, $\varepsilon_{y / n}$ : relative error of spread of wingend. 
べて $S P=5 \mathrm{~m}$ として行った。

\section{結果およひ考察}

網水深およびオッター水深 Fig. 3 は，上祀の解析法

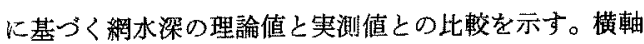
は理諭值，縦軸は実測值で，ワーブ長 $300 \mathrm{~m}$ 扰よび 500 $\mathrm{m}$ の电網速度 2.5 ノット以下の点を除いては，いずれ8 再軸に対する $45^{\circ}$ 線上に活ほ均等に分布していると見な せる。ワープ長 $300 \mathrm{~m}$ 拉よび $500 \mathrm{~m}$ の低速時に特いて， 両者の間に多少差が生じたのは，前報衫の結果より芙測

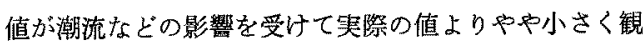
测されたのではないかと考党られる。しかし，全体を通 して理論值の奏測值に対する相対誤差は，ロープ長 100 $\mathrm{m}, 200 \mathrm{~m}, 300 \mathrm{~m}, 400 \mathrm{~m}, 500 \mathrm{~m}$ の順に, それぞれ 9.1, $10.9,7.6,4.7,7.1 \%$ で, 全体の平均で $8 \%$ 以内に納ま っている。

次に，才ッター水深の理論值と実測值の比較を Fig. 4 に示す。Fig. 3 と同様に，横軸は理論值，綎軸は头測值 である。同图からオッタ一水深は網水深上りも両者で よく一致していることが分かる。網水深と同じく理論值

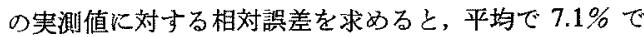
あった。これらのことから，上記の解析法を用いて，か なりの精度で中㬐トロールの網水深およびオッター水深 は計算で求めることができる。

袖網間隔 中層トロールは诋电と同様に，曳䋧によっ て網口を通る海水を淐過する過程で漁獲が確定され，大 きな網口が漁獲効率の向上につながるものになる。した がって，操業中の網口形状を予湘することは大きな意味 がある。しかし，過去の近似計算法において，袖網間隔

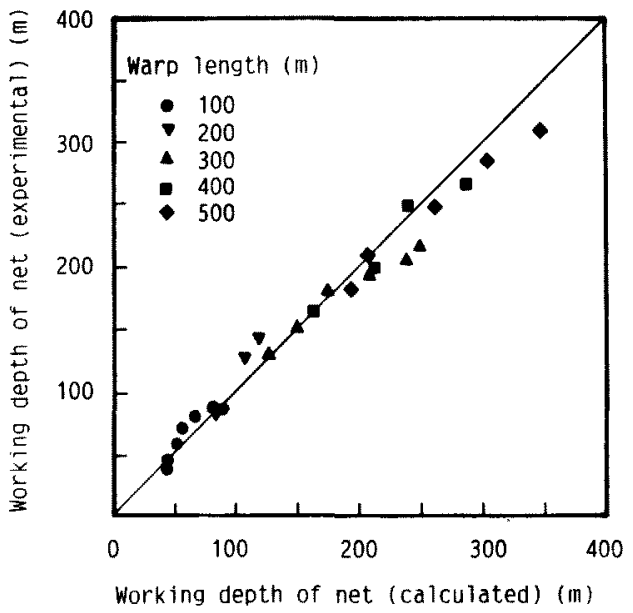

Fig. 3. Comparison between the experimental and calculated values of the working depth of net.

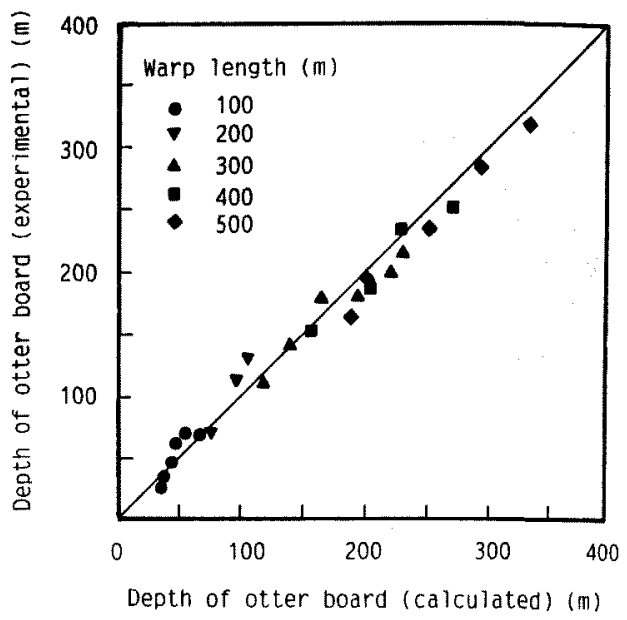

Fig. 4. Comparison between the experimental and calculated values of the working depth of otter board.

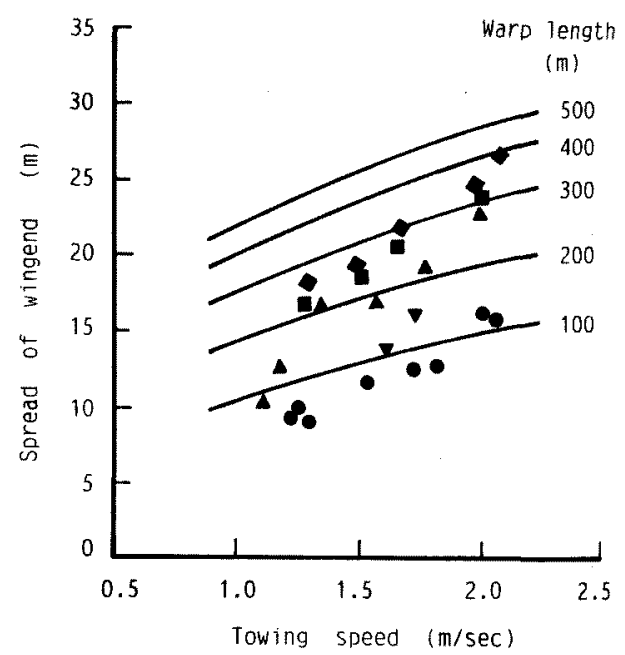

Fig. 5. Comparison between the experimental and calculated values of the spread of wingend. Each symbols show the experimental values at different warp length $(100 \mathrm{~m}$; $\checkmark$ $200 \mathrm{~m} ; \quad 300 \mathrm{~m} ; 400 \mathrm{~m} ; \bullet 500 \mathrm{~m})$.

まで論した研究は少ない。本文では袖網間隔の理論計算 ができたので，それを実測值と此較したのが Fig.5であ る。同図より, 袖網間隔のワープ長に対与る変化は, 画 者がほぼ同様な頃向が示されたものの，ワープ長が長く なると，理論值の実測值に対する差す大きくなることが 認められた。特に実測值の方が曳網速度に対する袖絧間 隔の增加が急である。このことは，操紧時に挌けるオッ ターボードが常に揚力の最も優れた状態に保たれる前提 に大きな原因があると思われる。 


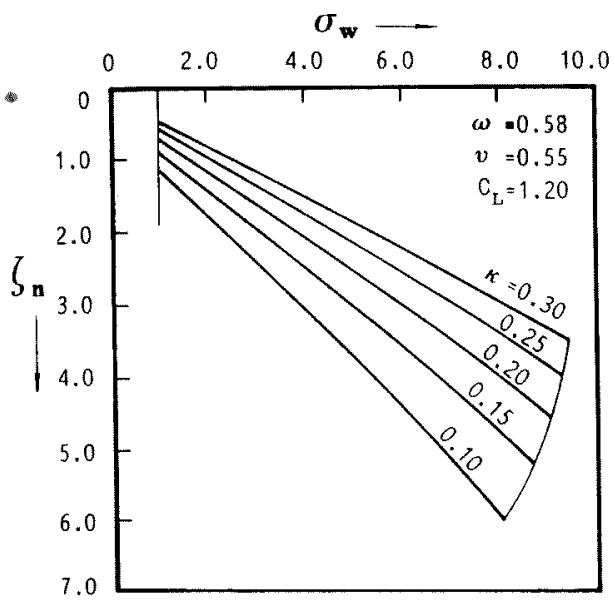

Fig. 6. Comparison of the values of $\zeta_{n}$ and $\sigma_{w}$ at different values of $\kappa$.

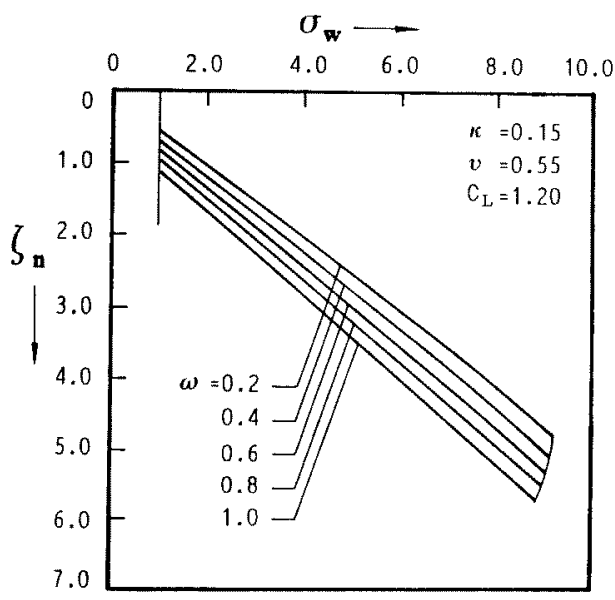

Fig. 7. Comparison of the values of $\zeta_{n}$ and $\sigma_{w}$ at different values of $\omega$.

\section{網水深および袖網間隔に及ほす各種パラメータ值の影}

響 ここでは, 各種パラメータ $\kappa, \omega, \sigma_{u}\left(=l_{w} / l_{n},\left(l_{w}\right.\right.$ ：ワ 一プ長))拉よび $C_{L}$ などの值の变化によって, 網の水深 $\left(z_{n}\right)$ 括よび袖絧間附 $\left(y_{n}\right)$ がどの上うに变化するかを調 ベることにする。たたし，各種パラか一タを类用的な範 用内に各々独立に变化させたとき，他のパラメータの值 は以上の計算に用いた值をその立引引用した。

Fig. 6〜9 に，計算された結果在無次元化で示す。

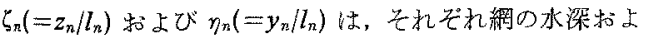
び袖網閔隔を表す無次元量である。これらの計算結果か ら、炏のことか分かった。

Fig. 6 た和いて，船速に関するパラィータ๙を0.1〜

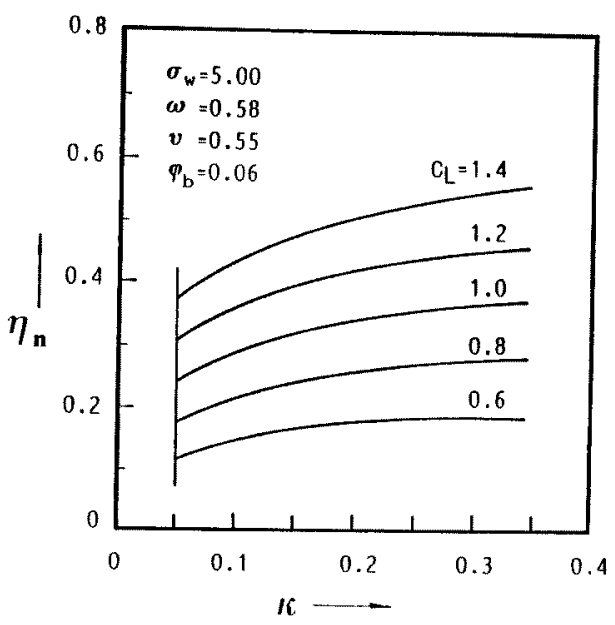

Fig. 8. Comparison of the values of $\eta_{n}$ and $\kappa$ at different values of $C_{L}$.

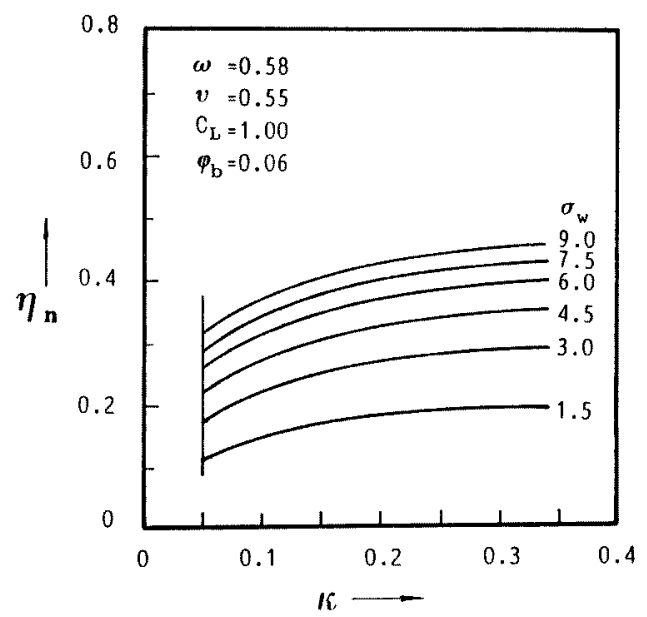

Fig. 9. Comparison of the values of $\eta_{n}$ and $\kappa$ at different values of $\sigma_{w}$.

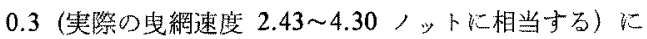

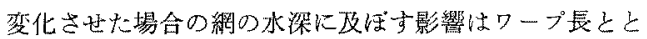
もに大きくなる。しかし，反が大妾くなるに従ってその

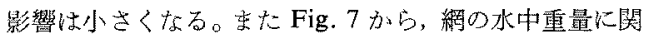

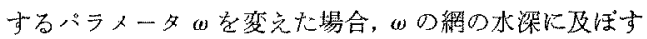
影諳は無視できない程度ですることがわかる。

Fig. 8 は，ォターボードの掦力係数 $\left(C_{L}\right)$ をバラィ 一夕としたときの袖絧間隔 $\left(\eta_{n}\right)$ と船速 $(\kappa)$ の夙係である

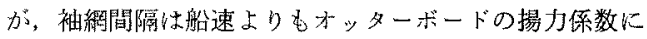
大きく左右される。が船速 4.30 ノット下相当した場 合，オッターボードの掦力係数を 0.6 から 1.4 飞增加さ せたとき，袖網間隔は 3 倍も增えるという結果を得た。 一方、ワーブ長の変化による袖網間隔への影響は, Fig. 
9 に示すように極めて大きい。しかし，ワープの長さが 長くなるとその影瀄俚小さくなる。

な预, 本研究は文部省科学研究費補助金一般研究 01560202 の援助のもとで行われた。記して謝意を表わ 士。

$$
\text { 文献 }
$$

1）宮崎芳夫：日水踗，36，48-57 (1970).

2）宮崎芳夫：日水誌，36，58-67 (1970).

3）宮㟉芳夫：日水誌，38，1215-1222 (1972).
4）宮崎芳夫：日水范，38，1223-1228 (1972).

5）传藤 要，宫岎芳夫：日水誌， 50，793-804 (1984).

6) K. Nakasai and T. Kawakami: Nippon Suisan Gakkaishi, 31, 277-280 (1965).

7) X. W. She, C. D. Yu, and F.X. Hu: Journ. Zhejiang Coll. Fish., Vol. 3, 167-177 (1984).

8）仿藤 要, 官崎芳夫：日本航海学会論文集， 67, 11-20 (1982).

9) 松田 貯, 胡 夫祥, 估藤 要, 五月女雄二郎, 春日 功: 57, 日水誌, 655-660 (1991). 